International Journal of Medical Sciences

ISSN 1449-1907 www.medsci.org 2008 5(6):371-376

Research Paper

(C) Ivyspring International Publisher. All rights reserved

\title{
Inhalation with Fucose and Galactose for Treatment of Pseudomonas Aeruginosa in Cystic Fibrosis Patients
}

\author{
Hans-Peter Hauber ${ }^{1,2}{ }^{凶}$, Maria Schulz², Almuth Pforte ${ }^{2}$, Dietrich Mack ${ }^{3}$, Peter Zabel ${ }^{1}$, Udo Schumacher ${ }^{4}$
}

1. Medical Clinic, Research Center Borstel, Department of Medicine, Borstel, Germany.

2. Department of Medicine I, University Hospital Hamburg-Eppendorf, Germany.

3. Department of Microbiology and Immunology, University Hospital Hamburg-Eppendorf, Germany.

4. Department of Anatomy II: Experimental Morphology, University Hospital Hamburg-Eppendorf, Germany

$\square$ Correspondence to: Priv. Doz. Dr. med. Hans-Peter Hauber, Research Center Borstel, Department of Medicine, Parkallee 35, 23845 Borstel, Germany. Tel: (+)49-4537-188-0; Fax: (+)49-4537-188-313; E-mail: hphauber@fz-borstel.de

Received: 2008.08.24; Accepted: 2008.11.15; Published: 2008.11.17

Background: Colonisation of cystic fibrosis (CF) lungs with Pseudomonas aeruginosa is facilitated by two lectins, which bind to the sugar coat of the surface lining epithelia and stop the cilia beating.

Objectives: We hypothesized that $P$. aeruginosa lung infection should be cleared by inhalation of fucose and galactose, which compete for the sugar binding site of the two lectins and thus inhibit the binding of $P$. aeruginosa.

Methods: 11 adult CF patients with chronic infection with P. aeruginosa were treated twice daily with inhalation of a fucose/galactose solution for 21 days (4 patients only received inhalation, 7 patients received inhalation and intravenous antibiotics). Microbial counts of $P$. aeruginosa, lung function measurements, and inflammatory markers were determined before and after treatment.

Results: The sugar inhalation was well tolerated and no adverse side effects were observed. Inhalation alone as well as combined therapy (inhalation and antibiotics) significantly decreased P. aeruginosa in sputum $(\mathrm{P}<0.05)$. Both therapies also significantly reduced TNFa expression in sputum and peripheral blood cells $(\mathrm{P}<0.05)$. No change in lung function measurements was observed.

Conclusions: Inhalation of simple sugars is a safe and effective measure to reduce the P. aeruginosa counts in CF patients. This may provide an alternative therapeutical approach to treat infection with $P$. aeruginosa.

Key words: Cystic fibrosis, fucose, glactose, inhalation, lectin, Pseudomonas aeruginosa

\section{INTRODUCTION}

Chronic infection of the airways with $P$. aeruginosa is the leading cause of morbidity and mortality in the majority of CF patients (1). This pathogen colonises the airways and lungs often in the late teens or early twenties and can be controlled for a prolonged time by antibiotic treatment (2). However, during the long period of infection, it gets resistant towards chemotherapy and thus the infection cannot be controlled any longer. This situation will become more evident in the future as the pipeline for the development of antibacterial agents runs dry with only five new drugs likely to being approved within the next few years (3).

However, novel strategies to fight the infection may be developed by interfering with the bacterial attachment to the airway epithelium. P. aeruginosa produces two lectins, carbohydrate binding proteins, designated P. aeruginosa lectin I (PA-I or Lec A) and II
(PA-II or Lec B). The first one is specific for galactose, the second for fucose (4). Both lectins are used in two clever ways to facilitate its pathogenicity. First of all, the lectins attach to the covering epithelia by binding to the glycocalix of the mammalian cells. By adding simple sugars, this attachment can be blocked as shown in external otitis caused by $P$. aeruginosa (5). However, simple adhesion via lectin sugar interactions would not be enough to persist in the airways as the mucociliary elevator would remove all pathogens residing within mucus layer of the airways' lining fluid. As this elevator is driven by the beating of the cilia, their inactivation would also facilitate the infection, which is indeed the case as these two lectins also immobilise the cilia, thus making the mucociliary elevator ineffective (6). A case report demonstrated, that inhalation of galactose and fucose could indeed remove $\mathrm{P}$. aeruginosa from the airways of a non $\mathrm{CF}$ pa- 
tient even if conventional antibiotic treatment failed (7).

The aim of the present study was to investigate the effect of this galactose/fucose solution in CF patients with chronic infection with $P$. aeruginosa as at least the PA-II acts on cilia of CF patients in vitro in the same way as in normal controls (8).

\section{SUBJECTS AND METHODS}

\section{Study design}

This study was an open clinical trial. Adult CF patients were recruited from the $\mathrm{CF}$ outpatient clinic and the pulmonary ward of the Department of Medicine I, University Hospital Hamburg-Eppendorf. Patients had chronic infection with $P$. aeruginosa (proven by positive sputum cultures for at least three years) and acute exacerbation at time of recruitment. They were randomized to be treated with inhalation of a 10 $\mathrm{ml}$ of $0.1 \mathrm{M}$ fucose / $0.1 \mathrm{M}$ galactose solution in $0.9 \%$ $\mathrm{NaCl}$ twice daily for 21 days either in the presence or absence of therapy with intravenous antibiotics (cephalosporine + aminogylcoside). The concentration of fucose and galacose was based on data from a previous study (6). Previous medication including inhaled antibiotics, vitamines, pancreatic enzymes, dornase alpha, bronchodilatators was continued. Sputum cultures, sputum cell counts, peripheral blood cell counts, lung function measurements (vital capacity, VC, forced expiratory volume in one second, FEV1), arterial oxygen pressure, inflammatory markers ( $\mathrm{C}$ reactive protein, IgG, IgE), liver function tests (GOT, GPT) and cytokine measurements (tumor necrosis factor- $\alpha$, interleukin-10) were performed before and after treatment. The study protocol was approved by the local Ethics Committee of the City of Hamburg, Germany.

\section{Sputum sampling}

After rinsing their mouth with sterile water patients coughed sputum into a sterile container. One part was immediately transported to the Department of Microbiology for bacterial culture. The other part was weighed, lyophylized with DTT and filtered through a nylon mesh. After centrifugation the cell pellet was redissolved into phosphate buffered saline (PBS) containing 2\% fetal calf serum (FCS; Seromed, Berlin, Germany). Cell numbers were counted and cytospins were prepared for differential cell counts.

\section{Peripheral blood mononuclear cells (PBMC) and serum samples}

PBMC were isolated by centrifugation over Ficoll-Paque (Pharmacia, Uppsala, Sweden) and washed twice with PBS containing 2\% FCS. PMBC were counted, cytospins were prepared and differential cell counts were preformed. Serum protein levels of tumor necrosis factor-a (TNFa) were determined using an enzyme linked immunosorbent assay (ELISA, R\&D Systems, Minneapolis, Minn, USA). C reactive protein (CRP), IgG, IgE, GOT, and GPT were measured using routine laboratory protocols.

\section{RNA preparation and RT-PCR}

Sputum cell and PBMC samples, each containing RNAzol (Wak, Bad Soden, Germany) and 80,000 cells, were stored at $-20^{\circ} \mathrm{C}$ until further preparation. RNA was extracted by treatment with chlorofrome and precipitated with isopropanol. RNA was reverse-transcribed using $2 \mu \mathrm{l} 25 \mathrm{mM} \mathrm{MgCl} 2,1 \mu \mathrm{l}$ 10xPCR buffer, $1 \mu 110 \mathrm{mM}$ of each desoxynucleotide triphosphate (dNTP), $0.5 \mu \mathrm{l} 50 \mu \mathrm{M}$ OligodT, $0.5 \mu \mathrm{l} 20$ $\mathrm{U} / \mu \mathrm{l}$ RNAse inhibitor and $0.5 \mu \mathrm{l} 50 \mathrm{U} / \mu \mathrm{l}$ reverse transcriptase (Perkin Elmer Biosystemsm Roche, Branchburg, USA). The mixture was incubated at $42^{\circ} \mathrm{C}$ for $30 \mathrm{~min}$ and at $99^{\circ} \mathrm{C}$ for $5 \mathrm{~min}$. Samples were stored at $-20^{\circ} \mathrm{C}$ until amplification.

The resultant cDNA was amplified by PCR in a thermal cycler (Hybaid, Teddington, United Kingdom) with a final volume of $100 \mu$ l containing $10 \mu \mathrm{l}$ cDNA (IL-18, IL-10) or $5 \mu \mathrm{l}$ cDNA ( $\beta$-actin), $10 \mu \mathrm{l}$ or $15 \mu \mathrm{l}$ dilution buffer, $8 \mu 112 \mathrm{mM} \mathrm{MgCl}_{2}, 8 \mu \mathrm{l}$ 10xPCR buffer, $55.5 \mu \mathrm{l}$ DEPC- $\mathrm{H}_{2} \mathrm{O}, 0.5 \mu \mathrm{l} / \mu \mathrm{l}$ recombinant Taq DNA polymerase (Perkin Elmer Biosystems, Roche, Branchburg, USA) and $2.0 \mu 115 \mathrm{mmol}$ of each primer. $\beta$-actin served as control. The oligonucleotide primers for PCR were based on published mRNA sequences. The human $\beta$-actin primers were $5^{\prime}$-GTG GGG CGC CCC AGG CAC CA-3' for the upstream primer and 5'-CTC CTT AAT GTC ACG CAC GAT TTC-3' for the downstream primer. TNFa utilized 5'-CAG AGG GAA GAG TTC CCC AG-3' for the upstream primer and 5'-CCT TGG TCT GGT AGG AGA CG-3' for the downstream primer. PCR amplification for $\beta$-actin was performed for 36 cycles $\left(1 \mathrm{~min}\right.$ at $94^{\circ} \mathrm{C}, 1 \mathrm{~min}$ at $60^{\circ} \mathrm{C}$, $40 \mathrm{sec}$ at $\left.72^{\circ} \mathrm{C}\right)$ and for TNFa for 40 cycles $(1 \mathrm{~min}$ at $94^{\circ} \mathrm{C}, 1 \mathrm{~min}$ at $60^{\circ} \mathrm{C}, 40$ seconds at $72^{\circ} \mathrm{C}$ ).

\section{Identification of $P C R$ products}

PCR products were analyzed by electrophoresis on a $2 \%$ agarose gel containing ethidium bromide and visualized with UV light. The sizes of the PCR products were compared with the expected PCR product length using a molecular weight marker (Boehringer, Mannheim, Germany) ran in parallel.

\section{Densitometric and semiquantitative PCR analysis}

Densitometric analysis was performed with the Eagle Eye II Still Video Systeme (Stratagene, La Jolla, 
USA). The expression was standardized to that of $\beta$-actin expression from the same reverse-transcribed TNFa or IL-10 mRNA sample. Ratios of cytokine: $\beta$-actin were calculated for semiquantitative RNA expression measurement as previously described (9).

\section{Statistics}

An overall ANOVA, followed by multiple testing with the Bonferroni correction, was performed. Differences between conditions were assessed by means of post hoc pairwise comparison with the Dunnet test. A P value of less than 0.05 was considered statistically significant. All values are given as means \pm SEM if not otherwise stated.

\section{RESULTS}

\section{Patient characteristics}

A total number of 11 patients ( 8 male, 3 female, median age 27 years) were included. 4 patients were treated with inhalation only, 7 patients received inhalation and antibiotics. Table 1 summarizes the demographics of both groups.

TABLE 1: Patient group characteristics

\begin{tabular}{lll}
\hline & p. i. & p. i. + i. v. \\
$\mathrm{N}$ & 4 & 7 \\
\hline Male/female & $2 / 2$ & $3 / 4$ \\
\hline Age (years) & $35.2 \pm 5.0$ & $31.3 \pm 3.5$ \\
\hline
\end{tabular}

P. i.: Inhalation alone. P. i. +i.v: Inhalation + i. v. antibiotics. Mean \pm SEM

\section{Fucose/galactose inhalation reduces $P$. aeruginosa in sputum}

Inhalation with fucose/galactose solution alone significantly decreased $P$. aeruginosa in sputum $(1.032 .500 \pm 561.714$ bacteria/ml pre vs $527.525 \pm$ 302.347 bacteria $/ \mathrm{ml}$ post) $(\mathrm{P}<0.05)$. Combination of inhalation and intravenous antibiotics also significantly reduced bacterial load in sputum (1.007.000 \pm 254.215 bacteria/ $\mathrm{ml}$ pre vs $500.366 \pm 223.592$ bacte$\mathrm{ria} / \mathrm{ml}$ post $)(\mathrm{P}<0.05)$. The reduction of $P$ aeruginosa in sputum by inhalation alone compared to combined therapy was similar. There was no significant difference between both treatment regimens $(P>0.05)$ (Figure 1).

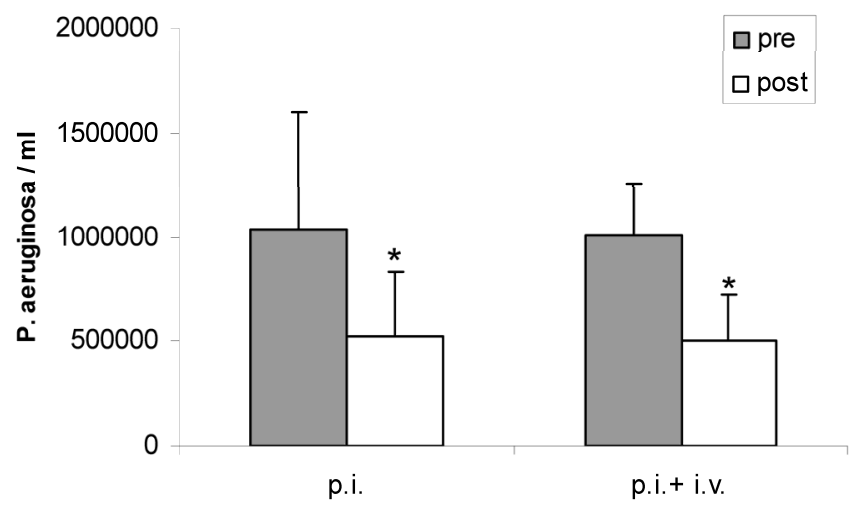

Figure 1: Sputum counts of $P$. aeruginosa before (pre) and after (post) treatment with inhalation alone (p. i.) or combined treatment with inhalation and i. v. antibiotics (p. i. + i. v.). Mean+SEM. *: $\mathrm{P}<0.05$ vs pre.

\section{Fucose/galactose inhalation decreases sputum neu- trophils}

The number of inflammatory cells in sputum was not significantly altered by either inhalation alone $(\mathrm{P}>$ $0.05)$ or combined therapy $(p=0.06)$. However, inhalation alone significantly decreased the percentage of sputum neutrophils $(95.5 \pm 1.5 \%$ pre vs $84.0 \pm 2.0 \%$ post $)(\mathrm{P}<0.05)$ and significantly increased the percentage of sputum macrophages $(3.0 \pm 0.0 \%$ pre vs 11.0 $\pm 1.0 \%$ post $)$ and sputum lymphocytes $(0.5 \pm 0.5 \%$ pre vs $2.5 \pm 0.5 \%$ post $)(\mathrm{P}<0.05)$ (Table 2$)$. In contrast no significant changes were observed with combined therapy $(\mathrm{P}>0.05)$. In peripheral blood inhalation alone and combined therapy did not significantly alter the numbers or precentages of PBMC $(\mathrm{P}>0.05)$.

TABLE 2: Inflammatory cells in sputum

\begin{tabular}{lllll}
\hline & & p.i. & p.i. + i.v. \\
Macrophages (\%) & Pre & $3.0 \pm 0.0$ & $7.2 \pm 3.2$ \\
& Post & $11.0 \pm 1.0^{*}$ & $3.5 \pm 1.2$ \\
\hline Lymphocytes (\%) & Pre & $0.5 \pm 0.5$ & $2.3 \pm 0.9$ \\
\hline \multirow{2}{*}{ Neutrophils (\%) } & Post & $2.5 \pm 0.5^{*}$ & $2.3 \pm 1.3$ \\
& Pre & $95.1 \pm 1.5$ & $90.2 \pm 3.8$ \\
\hline Eosinophils (\%) & Post & $84.0 \pm 2.0^{*}$ & $93.8 \pm 1.8$ \\
& Pre & $1.0 \pm 1.0$ & $0.3 \pm 0.2$ \\
\hline
\end{tabular}

P. i.: Inhalation alone. P. i. +i.v: Inhalation + i. v. antibiotics. Pre: before treatment. Post: after treatment. Mean \pm SEM. *: $\mathrm{P}<0.05$ vs pre.

\section{Fucose/galacatose inhalation does not compromise pulmonary function}

There were no significant changes in $\mathrm{pO}_{2}, \mathrm{VC}$ or FEV1 with inhalation alone or combined therapy (P > 0.05; data not shown). 


\section{Fucose/galactose inhalation decreases TNFa ex- pression}

Both inhalation alone and combined therapy significantly decreased TNFa mRNA expression in sputum cells $(1.31 \pm 0.53$ pre vs $0.54 \pm 0.0$ post and $0.94 \pm$ 0.39 pre vs $0.31 \pm 0.13$ post $)(\mathrm{P}<0.05)$ (Figure $2 \mathrm{~A})$ and in PBMC $(0.45 \pm 0.29$ pre vs $0.24 \pm 0.04$ post and $0.29 \pm$ 0.17 pre vs $0.02 \pm 0.20$ post) $(\mathrm{P}<0.05)$ (Figure $2 \mathrm{~B})$. Expression of IL-10 mRNA was not significantly changed by treatment $(\mathrm{P}>0.05$; data not shown). TNFa serum protein levels were significantly decreased after treatment with fucose/galactose inhalation alone $(\mathrm{P}<$ $0.05)$ but not with combined therapy $(\mathrm{P}>0.05)$ (Figure 3).
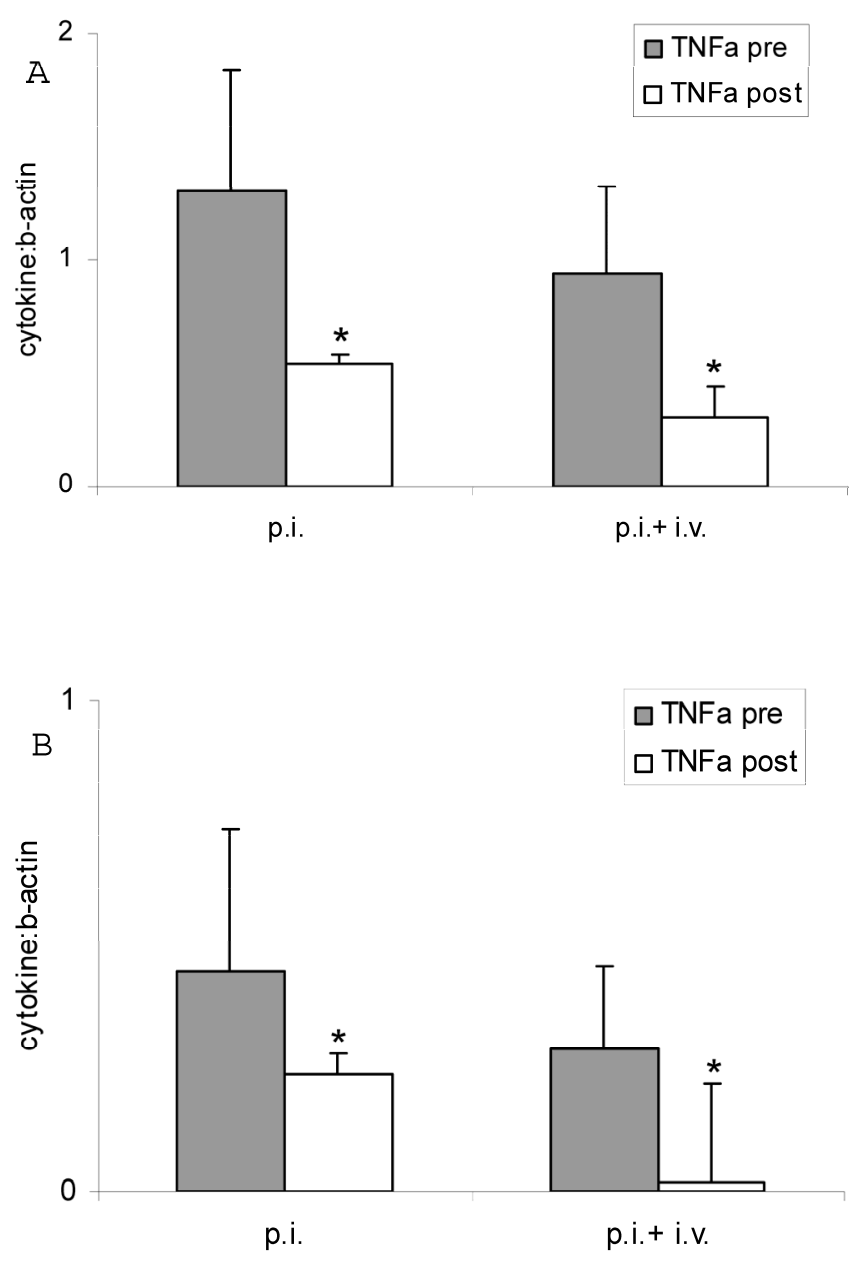

Figure 2: TNF $\alpha$ mRNA expression in sputum cells (A) and in PBMC (B) before (pre) and after (post) treatment with inhalation alone (p. i.) or combination of inhalation with antibiotics ( $p$. i. + i. v.). Mean+SEM. *: $\mathrm{P}<0.05$ vs pre.

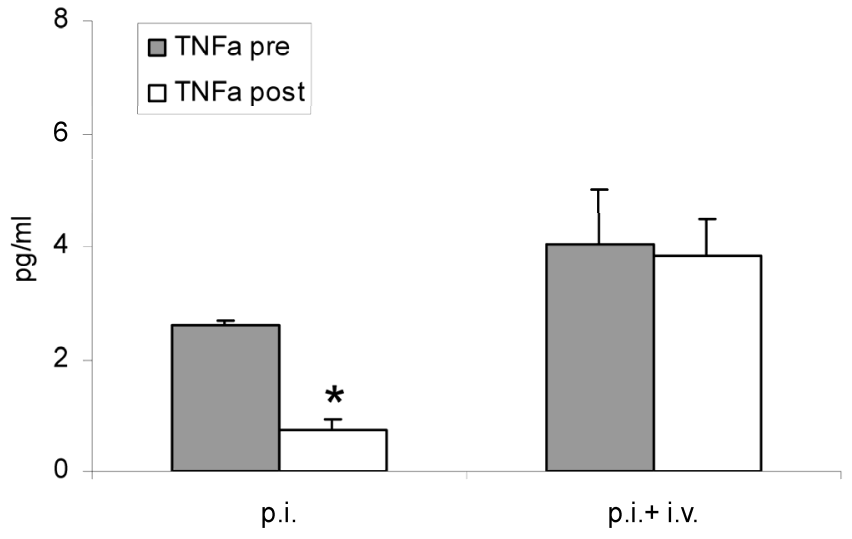

Figure 3: TNF $\alpha$ serum protein levels before (pre) and after (post) treatment with inhalation alone (p. i.) or combined treatment with inhalation and i. v. antibiotics (p. i. + i. v.). Mean+SEM. *: $\mathrm{P}<0.05$ vs pre.

\section{Fucose/galactose inhalation does not affect in- flammatory markers and liver function}

No significant changes of CRP levels, leukocyte counts, IgG levels, IgE levels, GOT levels, and GPT levels were observed after inhalation alone or combined therapy $(\mathrm{P}>0.05$, data not shown).

\section{DISCUSSION}

In the present study we found that inhalation with fucose/galactose could reduce $P$. aeruginosa and neutrophils in sputum as well as TNFa expression in sputum and peripheral blood of CF patients with acute exacerbation. Combination with intravenous antibiotics had no additional effect.

In our study we used fucose/galactose solution to block $P$. aeruginosa lectins PA-I and PA-II as an alternative approach to reduce airway colonisation with this bacteria. P. aeruginosa lectins PA-I and PA-II that bind to fucose and galactose contribute to the vilrulence of this bacterium (10). Therefore blocking of these lectins may prevent ongoing colonization and inflammation. Although fucose/galactose has been demonstrated to be effective in vitro and in vivo (6-8) at present there is no information available on the clinical effect of fucose/galacatose when given to $\mathrm{CF}$ patients.

In the present study both inhalation of fucose/galactose solution alone and combined therapy of inhalation and antibiotics decreased $P$. aeruginosa load in sputum. Previous studies used hypertonic saline solution or mannitol as inhalation treatment in $\mathrm{CF}$ (11-14). Inhalation with hypertonic saline solution resulted in improved lung function and reduced exacerbation rate $(12,13)$. There was also a trend towards decline of $P$. aeruginosa in sputum $(12,13)$. Inhalation with mannitol improved cough clearance in CF patients but its long-term effectiveness has not been de- 
termined yet (14). In the present study we cannot rule out the possibility that part of the effect may be due to hypertonicity. However, this does not preclude that fucose/galactose solution blocks $P$. aeruginosa lectins and that this is the most important effect. Of course an experimental control that inhaled another sugar that is not a strong binder to PA lectins would have been useful to further support the notion that the effect of fucose/galactose is due to restoration of the mucocilliary elevator and not due to hypertonicity. We did not include another control group because it has been clearly shown in previous experiments that fucose and galactose can prevent binding of PA lectins I and II (8, 15). In those studies inhibition of ciliary beats due to PA lectins was quantified as well as restoration by adding fucose and/or galactose $(8,15)$.

Inhalation alone but not combined therapy ameliorated inflammatory cell patterns in sputum (less neutrophils). This data are surprising. It seems that inhalation alone can clear bacteria from the airways without a strong inflammatory response due to physical elimination of $P$. aeruginosa via the mucociliary elevator. On the other hand it has to be taken into account that interaction of $P$. aeroginosa with antibotics is complex as "subinhibitory" concentrations of antibiotics leads to the suppression of lectin synthesis via the quorum sensing system (16). Antibiotics may therefore reduce the effectiveness of fucose/galactose. This remains to be further evaluated. On the other hand both treatment options significantly reduced TNFa mRNA expression in sputum cells and PBMC. This finding agrees with the hypothesis that antibiotic as well as inhalation therapy has an anti-inflammatory effect. Interestingly we only observed a significant reduction of TNFa serum protein levels with inhalation alone but not with combination therapy. It is tempting to speculate that fucose/galacatose inhalation may be able to clear bacteria from the lungs without inducing inflammation. However, this has to be further evaluated.

There was no significant increase in lung function measurements after inhalation or combined therapy. This is mostly due to the small number of patients and short period of time studied.

As the fucose/galactose inhalation is a novel treatment, an important question concerns the observation of adverse effects of this treatment. In the present study fucose/galactose inhalation was well tolerated and had no adverse effect on liver function. However, this does not rule out the possibility that over a prolonged period of treatement adverse effects may occur. Interestingly, most patients reported a relief from symptoms after inhalation. This may be due to lowering the viscosity of mucus.
As already mentioned inhalation with fucose/galactose to reduce $P$. aeruginosa in CF patients is a novel therapeutic approach that has never been performed previously. However, the main weakness of the present study is the small numbers of patients studied and the comparison of inhalation versus inhalation + antibiotics. Moreover, patients with exacerbation but not patients with stable disease were investigated. Inhalation with fucose/galactose has never been used before in a clinical trial with CF patients. For methodical considerations we chose patients with chronic infection with $P$. aeruginosa who had an exacerbation because these patients are likely to have high numbers of $P$. aeruginosa in sputum. This makes it easier to observe an effect in reducing bacterial load. For ethical issues we divided the study arms in a ratio of 1:2 (inhalation: inhalation + antibiotics). This ensured that most of the patients were treated with antibiotics and that an effect of inhalation alone and inhalation with antibiotics could be evaluated.

Of course the adequate control would have been inhalation with the diluting solution for fucose and galactose. However, this study was planned as a pilot study to see whether fucose/galactose would have any effect. Further studies are warranted to compare fucose/galacatose to other inhalations (eg hypertonic saline).

In conclusion the findings in this report show that inhalation with fucose/galactose solution could reduce $P$. aeruginosa in sputum of adult CF patients with chronic infection with this bacterium. It was well tolerated and no serious side effects were observed. Local inflammation in the lungs may be attenuated by removal of $P$. aeruginosa. Future studies will have to compare the effect of inhalation with fucose/galactose solution with other inhalation regimens. It will also be necessary to define which patients are likely to profit the most and whether it should be used in regular intervals or not.

\section{Conflict of Interest}

The authors declare no conflict of interest. This study was registered at the University of Hamburg, Germany.

\section{References}

1. Davis PB, Drumm M, Konstan MW: Cystic fibrosis. Am J Respir Crit Care Med 1996; 154: 1229-1256.

2. Gibson RL, Burns JL, Ramsey BW: Pathophysiology and management of pulmonary infections in cystic fibrosis. Am J Respir Crit Care Med 2003; 168: 918-951.

3. Nelson R: Antibiotic development pipeline runs dry. Lancet 2003; 362: 1726-1727.

4. Gilboa-Garber N: Pseudomona aeruginosa lectins. Methods Enzymol 1982; 83: 378-385. 
5. Steuer MK, Herbst H, Beuth J, Steuer M, Pulverer G, Matthias R: Hemmung der bakteriellen Adhäsion durch Lektinblockade bei durch Pseudomonas aeruginosa induzierter Otitis externa im Vergleich zur lokalen Therapie mit Antibiotika (German). Otorhinologica Nova 1993; 3: 19-25.

6. Adam EC, Mitchell BS, Schumacher DU, Grant G, Schumacher U: Pseudomonas aeruginosa lectin II stops human ciliary beating: Therapeutic implications of fucose. Am J Respir Crit Care Med 1997; 155: 2102-2104.

7. von Bismarck P, Schneppenheim R, Schumacher U: Successful treatment of Pseudomonas aeruginosa respiratory tract infection with a sugar solution - a case report on a lectin based therapeutic principle. Klin Pädiatr 2001; 213: 285-287.

8. Adam EC, Schumacher DU, Schumacher U: Cilia from a cystic fibrosis patient react to the ciliotoxic Pseudomonas aeruginosa II lectin in a similar manner to normal control cilia - a case report. J Laryngol Otol 1997; 111: 760-762.

9. Hancock A, Armstrong L, Gama R, Millar A: Production of interleukin 13 by alveolar macrophages from normal and fibrotic lung. Am J Respir Cell Mol Biol 1998; 18: 60-65.

10. Mitchell E, Houles C, Sudakevitz D, et al: Structural basis for oligosaccharide mediated adhesion of Pseudomonas aeruginosa in the lungs of cystic fibrosis patients. Nat Struct Biol 2002; 9: 918-921.

11. Wark PA, McDonald V: Nebulised hypertonic saline for cystic fibrosis. Cochrane Database Syst Rev 2003; 1: CD001506.

12. Donaldson SH, Bennett WD, Zeman KL, Knowles MR, Tarran R, Boucher RC: Mucus clearance and lung function in cystic fibrosis with hypertonic saline. N Engl J Med 2006; 354: 241-250.

13. Elkins MR, Robinson $M$, Rose BR, Habour $C$, Moriarty $C P$, Marks GB, Belousova EG, Xuan W, Bye PT: National Hypertonic Saline in Cystic Fibrosis (NHSCF) Study Group. A controlled trial of long-term inhaled hypertonic saline in patients with cystic fibrosis. N Engl J Med 2006; 354: 229-240.

14. Robinson M, Daviskas E, Eberl S, Baker J, Chan HK, Anderson SD, Bye PT: The effect of inhaled mannitol on bronchial mucus clearance in cystic fibrosis patients: a pilot study. Eur Respir J 1999; 14: 678-685.

15. Mewe M, Tielker D, Schönberg R, Schachner M, Schumacher U, Jaeger KE: Pseudomonas aeruginosa lectins -I and -II and their interaction with human airway cilia. J Laryngol Otol 2005; 119: 595-599.

16. Sofer D, Gilboa-Garber N, Belz A, Garber NC: "Subinhibitory" erythromycin represses production of Pseudomonas aeruginosa lectins, autoinducer and virulence factors. Chemotherapy 1999; 45: 335-341. 